\title{
Associations of education and income with hazardous drinking among postpartum women in Japan: results from the TMM BirThree Cohort Study
}

Keiko Murakami ${ }^{1,2^{*}}$ D, Mami Ishikuro ${ }^{1,2}$, Fumihiko Ueno ${ }^{1,2}$, Aoi Noda ${ }^{1,2,3}$, Tomomi Onuma ${ }^{1}$, Fumiko Matsuzaki ${ }^{1}$, Hirohito Metoki ${ }^{1,4}$, Taku Obara ${ }^{1,2,3}$ and Shinichi Kuriyama ${ }^{1,2,5}$

\begin{abstract}
Background: Although the postpartum period is suggested to provide an ideal opportunity for interventions to prevent hazardous drinking, evidence on the associations of education and income with hazardous drinking during this period is limited, including in Japan.

Methods: We analyzed data from 11,031 women who participated in the Tohoku Medical Megabank Project Birth and Three-Generation Cohort Study in Japan. Hazardous drinking was defined as ethanol intake of $\geq 20 \mathrm{~g} /$ day 1 year after delivery. We conducted multiple logistic regression analyses to examine whether educational attainment or equivalent household income was associated with hazardous drinking, adjusting for age, parity, drinking status during pregnancy, work status, postpartum depression, breastfeeding, and income/education. We also conducted stratified analyses by income and education groups.

Results: The prevalence of hazardous drinking 1 year after delivery was 3.6\%. Lower education was associated with hazardous drinking; the odds ratio (95\% confidence interval) of high school education or lower compared with university education or higher was 2.17 (1.59-2.98). Lower income was also associated with hazardous drinking, but this association disappeared after further adjustments for education; the odds ratios (95\% confidence intervals) of the lowest compared with highest level of income were $1.42(1.04-1.94)$ and $1.12(0.81-1.54)$, respectively. A significant interaction was detected; lower education and lower income were associated with increased risks of hazardous drinking only in a lower income group and lower education group, respectively.

Conclusions: Postpartum women with lower education and lower income had higher risks of hazardous drinking in Japan.
\end{abstract}

Keywords: Education, Hazardous drinking, Income, Japan, Postpartum women

\footnotetext{
* Correspondence: mkeiko-tky@umin.ac.jp

${ }^{1}$ Tohoku Medical Megabank Organization, Tohoku University, 2-1

Seiryo-machi, Aoba-ku, Sendai, Miyagi 980-8573, Japan

${ }^{2}$ Graduate School of Medicine, Tohoku University, 2-1 Seiryo-machi, Aoba-ku,

Sendai, Miyagi 980-8575, Japan

Full list of author information is available at the end of the article
}

C C The Author(s). 2021 Open Access This article is licensed under a Creative Commons Attribution 4.0 International License, which permits use, sharing, adaptation, distribution and reproduction in any medium or format, as long as you give appropriate credit to the original author(s) and the source, provide a link to the Creative Commons licence, and indicate if changes were made. The images or other third party material in this article are included in the article's Creative Commons licence, unless indicated otherwise in a credit line to the material. If material is not included in the article's Creative Commons licence and your intended use is not permitted by statutory regulation or exceeds the permitted use, you will need to obtain permission directly from the copyright holder. To view a copy of this licence, visit http://creativecommons.org/licenses/by/4.0/. The Creative Commons Public Domain Dedication waiver (http://creativecommons.org/publicdomain/zero/1.0/) applies to the data made available in this article, unless otherwise stated in a credit line to the data. 


\section{Background}

Harmful use of alcohol is one of the leading risk factors for disease burden and causes substantial health loss [1]. Approximately 3 million deaths $(5.3 \%$ of all global deaths) and 132.6 million disability-adjusted life years (5.1\% of the global burden of disease and injury) were attributable to alcohol use in 2016 [2]. A hazardous volume of drinking is one of the most important aspects of the risk of alcohol use; a higher amount of alcohol consumed is associated with a higher risk of disease or death [3]. To design appropriate public health policies, it is crucial to identify the population groups that are most affected by hazardous drinking for targeted interventions.

Hazardous drinking is more common among women who are more highly educated and of higher income than among women of lower status in most Organisation for Economic Co-operation and Development (OECD) countries [4]. The patterns of women's drinking may change over their reproductive life course; most women reduce or abstain from alcohol use once they learn that they are pregnant [5], and many women have been found to return to drinking after their child is born $[6,7]$. This suggests that the postpartum period provides an ideal opportunity for interventions to prevent hazardous drinking. Limited evidence on the associations of education and income with hazardous drinking during the postpartum period is inconclusive in Western countries; some studies showed the associations of higher education and higher income with hazardous drinking $[6,8]$, while others showed no association [9, 10]. To our knowledge, no studies have examined the association of education and income with hazardous drinking among postpartum women in Asia, including Japan, although social and cultural contexts influence different social patterns of drinking in different countries [11]. Studies in Japan should be needed because Japanese women have unique characteristics of drinking. Unlike in other OECD countries, women with lower education in Japan have a higher risk of hazardous drinking [12], and income is not associated with hazardous drinking among women in Japan $[12,13]$.

Considering the above circumstances, we aimed to examine the associations of education and income with hazardous drinking among postpartum women in Japan. We focused on hazardous drinking 1 year after delivery because there is evidence that parenting a child $<1$ year of age is associated with reduced alcohol use and that this protective effect diminishes after 1 year postpartum [14].

\section{Methods}

\section{Study population}

We used data obtained from the Tohoku Medical Megabank Project Birth and Three-Generation Cohort Study
(TMM BirThree Cohort Study), which has been described elsewhere $[15,16]$. Pregnant women and their family members were contacted in approximately $50 \mathrm{ob}-$ stetric clinics or hospitals in Miyagi Prefecture when they scheduled their deliveries from 2013 to 2017. Tohoku University Tohoku Medical Megabank Organization established seven community support centers in Miyagi Prefecture as local facilities for voluntary admission-type recruitment and health assessment of the participants [17]. Trained genome medical research coordinators were placed in each clinic, hospital, or community support center to provide information on the TMM BirThree Cohort Study to potential participants and to receive signed informed consent forms from each participant. Of 32,986 pregnant women who were contacted, 22,493 agreed to participate. Among them, 10,288 women were excluded because of abortion or stillbirth, nonidentification of their birth status, incomplete questionnaires, no permission to transcribe their medical records, and pregnancy 1 year after delivery. Of the remaining 12,205 women, 1174 were excluded due to missing values for their drinking status 1 year after delivery, educational attainment, equivalent household income, parity, drinking status during pregnancy, work status, postpartum depression, or breastfeeding. The present study analyzed the remaining 11, 031 women (Fig. 1). The Ethics Committee of Tohoku University Tohoku Medical Megabank Organization reviewed and approved the TMM BirThree Cohort Study protocol (2013-1-103-1). The characteristics of the 11,031 analyzed women and the 11,462 excluded women are shown in Table $\mathrm{S} 1$.

\section{Measures}

Based on the questionnaire 1 year after delivery, educational attainment was categorized as high school or lower (elementary, junior high school, or senior high school), college (2-year college or special training school), and university or higher (university or graduate school). Using the questionnaire during pregnancy, the participants were asked to select their total annual household income from seven categories: $\leq 1.99,2.00$ $3.99,4.00-5.99,6.00-7.99,8.00-9.99,10.00-11.99$, and $\geq 12.00$ million Japanese yen (JPY). The equivalent household income was calculated as the household income divided by the square root of the number of family members [18]. The resulting value was categorized into four groups approximately corresponding to quartiles: $\leq 1.99,2.00-2.99,3.00-3.99$, and $\geq 4.00$ million JPY.

Using the questionnaire 1 year after delivery, the participants were asked to select one of the following response options for their drinking status: current drinker, past drinker, never-drinker, and constitutionally neverdrinker. Current drinkers were asked to report the types 


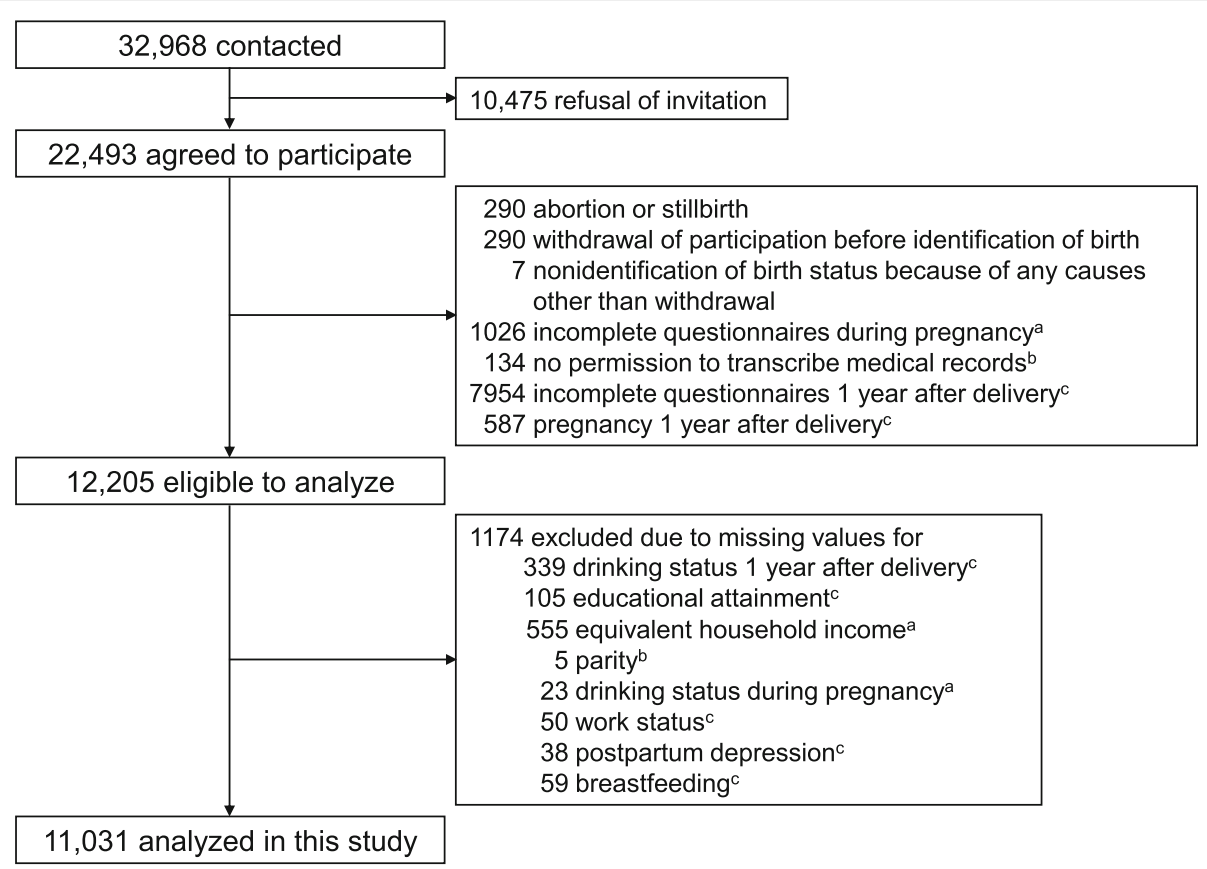

Fig. 1 Flow diagram of study participants in the present analysis of the TMM BirThree Cohort Study. ${ }^{\mathrm{a}}$ Data on equivalent household income and drinking status during pregnancy were obtained using questionnaires administered during pregnancy. ${ }^{b}$ Data on parity were obtained by transcribing medical records from obstetric clinics or hospitals. ${ }^{\circ}$ Data on pregnancy status 1 year after delivery, drinking status 1 year after delivery, educational attainment, work status, postpartum depression, and breastfeeding were obtained using questionnaires administered 1 year after delivery

of alcoholic beverages consumed as well as the frequency and amount of each consumption per day in the past year: sake (rice wine), shochu, beer, whisky, and/or wine. A score to each category of alcohol consumption frequency was assigned as follows: 7 for every day, 5.5 for 5-6 days/week, 3.5 for 3-4 days/week, 1.5 for 1-2 days/week, 0.5 for a few times/month, and 0 for almost never. The ethanol equivalent intake in grams was calculated as follows: $180 \mathrm{ml}$ sake $=23 \mathrm{~g}, 180 \mathrm{ml}$ shochu $=36$ g, $633 \mathrm{ml}$ beer $=23 \mathrm{~g}, 30 \mathrm{ml}$ whisky $=10 \mathrm{~g}$, and $100 \mathrm{ml}$ wine $=12 \mathrm{~g}$ [19]. Finally, the weekly ethanol equivalent intake was estimated by multiplying the amount of ethanol by the frequency score; the daily ethanol equivalent intake was calculated by dividing these estimates by 7 . Past drinkers, never-drinkers, and constitutionally neverdrinkers were considered abstainers and were assigned 0 g/day. The second term of Health Japan 21, which is a 10-year national plan begun in 2013, has established the targets relating to reducing the number of people drinking quantities of alcohol that increase the risk of lifestyle-related disease onset: ethanol intake of $\geq 40 \mathrm{~g} /$ day for men and $\geq 20 \mathrm{~g} /$ day for women [20]. Following this national recommendation, the threshold of hazardous drinking was defined as ethanol intake of $\geq 20 \mathrm{~g} /$ day in the present study. This is in line with the thresholds observed in several countries [4].
As covariates, we chose age, parity, drinking status during pregnancy, work status, postpartum depression, and breastfeeding. Age at delivery and parity were ascertained from the participants' medical records. Age at delivery was categorized as $\leq 29,30-34$, and $\geq 35$ years. Parity was dichotomized into nulliparous and multiparous. Using the questionnaire during pregnancy, the participants were asked to select one of the following responses concerning their drinking status: current drinker, past drinker, never-drinker, and constitutionally never-drinker. Responses were dichotomized into drinking (current drinker) and non-drinking (past drinker, never-drinker, and constitutionally never-drinker). Information on the participants' work status, postpartum depression, and breastfeeding was obtained from the questionnaire 1 year after delivery. The work status was dichotomized as working (permanent worker, selfemployed worker, temporary worker, or part-time worker) and not working (on leave, pensioner, housewife, student, or unemployed). The participants provided responses to the Japanese version of the Edinburgh Postpartum Depression Scale, which comprises 10 items assessing any symptoms of depression in the past 7 days [21]. Each item has four possible responses with scores of $0-3$, and the total score ranges from 0 to 30. Postpartum depression was defined as a score of $\geq 9$ [22]. All 
participants were also asked whether their child had been breastfed.

\section{Statistical analysis}

The characteristics of non-drinkers and drinkers 1 year after delivery were compared using the chi-square test. We conducted multiple logistic regression analyses to examine the associations of education and income with hazardous drinking 1 year after delivery. The odds ratios (ORs) and 95\% confidence intervals (CIs) were calculated for education and income, adjusted for age (model 1 ), as well as for parity, drinking status during pregnancy, work status, postpartum depression, and breastfeeding (model $2 \mathrm{a}$ for education and model $2 \mathrm{~b}$ for income). Income and education were then entered simultaneously in the same model (model 3). We also conducted sensitivity analyses restricted to only drinkers 1 year after delivery.

We entered the interaction term between education and income into the model and found that the interaction was statistically significant $(p<0.01)$. Based on this result, we also conducted stratified analyses of the association between education and hazardous drinking by income groups ( $\geq 3.00$ vs. $0-2.99$ million JPY) and the association between income and hazardous drinking by education groups (college or higher vs. high school or lower).

All analyses were conducted using the SAS version 9.4 software (SAS Institute Inc., Cary, NC, USA). For all analyses, a two-tailed $p$ value of $<0.05$ was considered statistically significant.

\section{Results}

Table 1 shows the characteristics of the study participants. About one-third of the participants had graduated from high school or lower. Among the participants, $2405(21.8 \%)$ were drinkers 1 year after delivery. Drinkers were more likely to be less educated, have a lower equivalent household income, be multiparous, be drinkers during pregnancy, and be classified as working and were less likely to breastfeed.

Table 2 shows the prevalence, ORs, and 95\% CIs for hazardous drinking 1 year after delivery. The prevalence of hazardous drinking was 3.6\%. Lower educational attainment was associated with an increased risk of hazardous drinking after adjusting for age (model 1) and after additionally adjusting for parity, drinking status during pregnancy, work status, postpartum depression, and breastfeeding (model 2a); the adjusted ORs of high school education or lower compared with university

Table 1 Characteristics of participants: the Tohoku Medical Megabank Project Birth and Three-Generation Cohort Study

\begin{tabular}{|c|c|c|c|c|c|c|c|}
\hline & \multirow{2}{*}{\multicolumn{2}{|c|}{ Total $(N=11,031)$}} & \multicolumn{4}{|c|}{ Drinking status 1 year after delivery } & \multirow{3}{*}{$\begin{array}{l}p \\
\text { value }^{a}\end{array}$} \\
\hline & & & \multicolumn{2}{|c|}{ Non-drinkers $(n=8626)$} & \multicolumn{2}{|c|}{ Drinkers $(n=2405)$} & \\
\hline & $\mathrm{n}$ & (\%) & $\mathrm{n}$ & (\%) & $\bar{n}$ & (\%) & \\
\hline Educational attainment & & & & & & & $<0.001$ \\
\hline University or higher & 3268 & (29.6) & 2602 & $(30.2)$ & 666 & $(27.7)$ & \\
\hline College & 4263 & $(38.7)$ & 3367 & $(39.0)$ & 896 & $(37.3)$ & \\
\hline High school or lower & 3500 & $(31.7)$ & 2657 & (30.8) & 843 & $(35.0)$ & \\
\hline Equivalent household income & & & & & & & 0.0073 \\
\hline$\geq 4.00$ million JPY & 2909 & (26.4) & 2271 & $(26.3)$ & 638 & $(26.5)$ & \\
\hline 3.00-3.99 million JPY & 2068 & $(18.7)$ & 1674 & $(19.4)$ & 394 & $(16.4)$ & \\
\hline 2.00-2.99 million JPY & 3514 & (31.9) & 2712 & (31.5) & 802 & (33.4) & \\
\hline$\leq 1.99$ million JPY & 2540 & $(23.0)$ & 1969 & (22.8) & 571 & $(23.7)$ & \\
\hline \multicolumn{8}{|l|}{ Covariates } \\
\hline Age & & & & & & & 0.13 \\
\hline$\leq 29$ years & 3226 & $(29.2)$ & 2512 & (29.1) & 714 & $(29.7)$ & \\
\hline 30-34 years & 4211 & $(38.2)$ & 3334 & (38.7) & 877 & $(36.5)$ & \\
\hline$\geq 35$ years & 3594 & (32.6) & 2780 & $(32.2)$ & 814 & (33.9) & \\
\hline Multiparous & 5761 & $(52.2)$ & 4327 & $(50.2)$ & 1434 & (59.6) & $<0.001$ \\
\hline Drinking during pregnancy & 701 & (6.4) & 357 & (4.1) & 344 & $(14.3)$ & $<0.001$ \\
\hline Working & 5815 & $(52.7)$ & 4382 & $(50.8)$ & 1433 & (59.6) & $<0.001$ \\
\hline Postpartum depression & 1423 & (12.9) & 1114 & $(12.9)$ & 309 & $(12.9)$ & 0.93 \\
\hline Breastfeeding & 6741 & $(61.1)$ & 6053 & $(70.2)$ & 688 & (28.6) & $<0.001$ \\
\hline
\end{tabular}

JPY, Japanese yen

${ }^{a}$ Obtained using the chi-square test, comparing non-drinkers and drinkers 
Table 2 Associations of education and income with hazardous drinking 1 year after delivery

\begin{tabular}{|c|c|c|c|c|c|c|}
\hline & $\begin{array}{l}\text { Hazardous } \\
\text { drinking/ } \\
\text { participants }\end{array}$ & (\%) & $\begin{array}{l}\text { Model } 1 \\
\text { OR }(95 \% \mathrm{CI})\end{array}$ & $\begin{array}{l}\text { Model } 2 a \\
\text { OR }(95 \% \mathrm{Cl})\end{array}$ & $\begin{array}{l}\text { Model } 2 b \\
\text { OR }(95 \% \mathrm{Cl})\end{array}$ & $\begin{array}{l}\text { Model } 3 \\
\text { OR }(95 \% \mathrm{CI})\end{array}$ \\
\hline Total & $397 / 11031$ & (3.6) & & & & \\
\hline \multicolumn{7}{|l|}{ Educational attainment } \\
\hline University or higher & $62 / 3268$ & (1.9) & 1.00 & 1.00 & & 1.00 \\
\hline College & $150 / 4263$ & (3.5) & $1.89(1.40-2.55)$ & $1.65(1.22-2.24)$ & & $1.62(1.19-2.22)$ \\
\hline High school or lower & $185 / 3500$ & (5.3) & $3.01(2.25-4.04)$ & $2.26(1.67-3.06)$ & & $2.17(1.59-2.98)$ \\
\hline \multicolumn{7}{|c|}{ Equivalent household income } \\
\hline$\geq 4.00$ million JPY & $83 / 2909$ & (2.9) & 1.00 & & 1.00 & 1.00 \\
\hline 3.00-3.99 million JPY & $46 / 2068$ & (2.2) & $0.80(0.56-1.16)$ & & $0.89(0.61-1.30)$ & $0.80(0.55-1.17)$ \\
\hline 2.00-2.99 million JPY & $143 / 3514$ & (4.1) & $1.51(1.15-1.99)$ & & $1.37(1.03-1.83)$ & $1.18(0.88-1.58)$ \\
\hline$\leq 1.99$ million JPY & $125 / 2540$ & $(4.9)$ & $1.87(1.40-2.49)$ & & $1.42(1.04-1.94)$ & $1.12(0.81-1.54)$ \\
\hline \multicolumn{7}{|l|}{ Covariates } \\
\hline \multicolumn{7}{|l|}{ Age } \\
\hline$\leq 29$ years & $101 / 3226$ & (3.1) & 1.00 & 1.00 & 1.00 & 1.00 \\
\hline 30-34 years & $153 / 4211$ & (3.6) & $1.17(0.90-1.51)$ & $1.34(1.03-1.76)$ & $1.28(0.98-1.67)$ & $1.37(1.05-1.79)$ \\
\hline$\geq 35$ years & $143 / 3594$ & (4.0) & $1.28(0.99-1.66)$ & $1.43(1.09-1.88)$ & $1.41(1.07-1.86)$ & $1.47(1.12-1.95)$ \\
\hline \multicolumn{7}{|l|}{ Parity } \\
\hline Nulliparous & $128 / 5270$ & (2.4) & 1.00 & 1.00 & 1.00 & 1.00 \\
\hline Multiparous & $269 / 5761$ & (4.7) & $1.94(1.56-2.41)$ & $1.90(1.52-2.37)$ & $1.81(1.42-2.29)$ & $1.76(1.39-2.24)$ \\
\hline \multicolumn{7}{|c|}{ Drinking status during pregnancy } \\
\hline Non-drinking & $328 / 10330$ & (3.2) & 1.00 & 1.00 & 1.00 & 1.00 \\
\hline Drinking & $69 / 701$ & (9.8) & $3.30(2.52-4.34)$ & $3.15(2.37-4.19)$ & $3.13(2.36-4.17)$ & $3.15(2.37-4.19)$ \\
\hline \multicolumn{7}{|l|}{ Work status } \\
\hline Not working & $161 / 5216$ & (3.1) & 1.00 & 1.00 & 1.00 & 1.00 \\
\hline Working & $236 / 5815$ & (4.1) & $1.33(1.08-1.63)$ & $1.16(0.94-1.43)$ & $1.14(0.92-1.40)$ & $1.17(0.95-1.45)$ \\
\hline \multicolumn{7}{|l|}{ Postpartum depression } \\
\hline No & $334 / 9608$ & (3.5) & 1.00 & 1.00 & 1.00 & 1.00 \\
\hline Yes & $63 / 1423$ & (4.4) & $1.32(1.00-1.74)$ & $1.22(0.92-1.62)$ & $1.21(0.91-1.61)$ & $1.20(0.90-1.59)$ \\
\hline \multicolumn{7}{|l|}{ Breastfeeding } \\
\hline Yes & $78 / 6741$ & $(1.2)$ & 1.00 & 1.00 & 1.00 & 1.00 \\
\hline No & $319 / 4290$ & (7.4) & 7.05 (5.48-9.07) & $6.75(5.23-8.71)$ & 7.07 (5.48-9.11) & $6.72(5.21-8.67)$ \\
\hline
\end{tabular}

$\mathrm{Cl}$, confidence interval; $J P Y$, Japanese yen; $O R$, odds ratio Model 1: adjusted for age (for all variables in the table)

Model $2 \mathrm{a}$ (for education) and $2 \mathrm{~b}$ (for income): model 1 + adjusted for parity, drinking status during pregnancy, work status, postpartum depression, and breastfeeding

Model 3: model 2 + adjusted for equivalent household income/educational attainment

education or higher were 3.01 (95\% CI, 2.25-4.04) and 2.26 (95\% CI, 1.67-3.06), respectively. This association was somewhat attenuated but did not disappear after further adjustments for equivalent household income (model 3); the corresponding OR was 2.17 (95\% CI, 1.59-2.98). Lower equivalent household income was associated with an increased risk of hazardous drinking after adjusting for age (model 1) and after additionally adjusting for parity, drinking status during pregnancy, work status, postpartum depression, and breastfeeding (model 2b); the adjusted ORs of $\leq 1.99$ million JPY compared with $\geq 4.00$ million JPY income were 1.87 (95\% CI, 1.40-2.49) and 1.42 (95\% CI, 1.04-1.94), respectively. This association disappeared after further adjustments for education (model 3); the corresponding OR was 1.12 (95\% CI, 0.81-1.54). Older age was associated with an increased risk of hazardous drinking after multivariate adjustments. Multiparity, drinking during pregnancy, and non-breastfeeding were associated with increased risks of hazardous drinking, while work status and postpartum depression were not associated with hazardous drinking. Sensitivity analyses restricted to 
Table 3 Associations between education and hazardous drinking 1 year after delivery according to income groups

\begin{tabular}{lllll}
\hline & $\begin{array}{l}\text { Hazardous } \\
\text { drinking/ } \\
\text { participants }\end{array}$ & $\mathbf{( \% )}$ & $\begin{array}{l}\text { Age-adjusted } \\
\text { OR (95\% Cl) }\end{array}$ & $\begin{array}{l}\text { Multivariate-adjusted }^{\mathbf{a}} \\
\text { OR (95\% Cl) }\end{array}$ \\
\hline $\begin{array}{l}\text { Educational attainment } \\
\text { Higher income group }(n=4977)\end{array}$ & & & & 1.00 \\
$\quad$ University or higher & $45 / 2082$ & $(2.2)$ & 1.00 & $1.27(0.85-1.90)$ \\
$\quad$ College & $58 / 1938$ & $(3.0)$ & $1.39(0.94-2.07)$ & $1.06(0.64-1.75)$ \\
$\quad$ High school or lower & $26 / 957$ & $(2.7)$ & $1.27(0.78-2.07)$ & 1.00 \\
Lower income group $(n=6054)$ & & & 1.00 & $2.54(1.50-4.31)$ \\
$\quad$ University or higher & $17 / 1186$ & $(1.4)$ & $2.84(1.69-4.79)$ & $3.83(2.29-6.40)$ \\
$\quad$ College & $92 / 2325$ & $(4.0)$ & $4.87(2.94-8.09)$ & \\
$\quad$ High school or lower & $159 / 2543$ & $(6.3)$ & & \\
\hline
\end{tabular}

$C l$, confidence interval; $O R$, odds ratio

Interaction between income groups and educational attainment: $p<0.001$. Equivalent household income was dichotomized into higher ( $\geq 3.00$ million Japanese yen) and lower (0-2.99 million Japanese yen) groups

${ }^{a}$ Adjusted for age, parity, drinking status during pregnancy, work status, postpartum depression, and breastfeeding

only drinkers 1 year after delivery produced similar results (Table S2).

Table 3 presents the prevalence, ORs, and 95\% CIs for hazardous drinking 1 year after delivery according to income groups. Lower educational attainment was associated with an increased risk of hazardous drinking not in a higher income group ( $\geq 3.00$ million JPY) but in a lower income group (0-2.99 million JPY); the adjusted ORs of high school education or lower compared with university education or higher were 1.06 (95\% CI, 0.64-1.75) and 3.83 (95\% CI, 2.29-6.40), respectively (interaction $p<$ $0.001)$.

Table 4 presents the prevalence, ORs, and 95\% CIs for hazardous drinking 1 year after delivery according to education groups. Lower equivalent household income was associated with an increased risk of hazardous drinking not in a higher education group (college or higher) but in a lower education group (high school or lower); the adjusted ORs of $\leq 1.99$ million JPY compared with $\geq 4.00$ million JPY income were 0.99 (95\% CI, 0.64$1.53)$ and 2.45 (95\% CI, 1.23-4.86), respectively (interaction $p=0.0085)$.

\section{Discussion}

The present study was performed to examine the associations of education and income with hazardous drinking among postpartum women in Japan. The prevalence of hazardous drinking 1 year after delivery was 3.6\%. Lower education was associated with an increased risk of hazardous drinking. Lower income was also associated with

Table 4 Associations between income and hazardous drinking 1 year after delivery according to education groups

\begin{tabular}{|c|c|c|c|c|}
\hline & $\begin{array}{l}\text { Hazardous } \\
\text { drinking/ } \\
\text { participants }\end{array}$ & (\%) & $\begin{array}{l}\text { Age-adjusted } \\
\text { OR }(95 \% \mathrm{Cl})\end{array}$ & $\begin{array}{l}\text { Multivariate-adjusted }^{2} \\
\text { OR }(95 \% \mathrm{Cl})\end{array}$ \\
\hline \multicolumn{5}{|c|}{ Equivalent household income } \\
\hline \multicolumn{5}{|c|}{ Higher education group ( $n=7531$ ) } \\
\hline$\geq 4.00$ million JPY & $73 / 2449$ & (3.0) & 1.00 & 1.00 \\
\hline 3.00-3.99 million JPY & $30 / 1571$ & (1.9) & $0.67(0.44-1.04)$ & $0.79(0.50-1.23)$ \\
\hline 2.00-2.99 million JPY & $71 / 2278$ & (3.1) & $1.13(0.81-1.57)$ & $1.08(0.76-1.53)$ \\
\hline$\leq 1.99$ million JPY & $38 / 1233$ & (3.1) & $1.12(0.75-1.67)$ & $0.99(0.64-1.53)$ \\
\hline \multicolumn{5}{|c|}{ Lower education group ( $n=3500)$} \\
\hline$\geq 4.00$ million JPY & $10 / 460$ & $(2.2)$ & 1.00 & 1.00 \\
\hline 3.00-3.99 million JPY & $16 / 497$ & (3.2) & $1.53(0.69-3.41)$ & $1.59(0.70-3.59)$ \\
\hline 2.00-2.99 million JPY & $72 / 1236$ & $(5.8)$ & $2.85(1.46-5.59)$ & $2.60(1.31-5.16)$ \\
\hline$\leq 1.99$ million JPY & $87 / 1307$ & (6.7) & $3.32(1.70-6.46)$ & $2.45(1.23-4.86)$ \\
\hline
\end{tabular}

$C l$, confidence interval; $J P Y$, Japanese yen; $O R$, odds ratio

Interaction between education groups and equivalent household income: $p=0.0085$. Educational attainment was dichotomized into higher (college or higher) and lower (high school or lower) groups

${ }^{a}$ Adjusted for age, parity, drinking status during pregnancy, work status, postpartum depression, and breastfeeding 
an increased risk of hazardous drinking, but this association disappeared after further adjustments for education. A significant interaction was detected between education and income; lower education and lower income were associated with increased risks of hazardous drinking only in a lower income group and lower education group, respectively.

The prevalence of hazardous drinking among women 1 year after delivery was $3.6 \%$. We could not directly compare the prevalence of hazardous drinking 1 year after delivery with corresponding data in Japan because there is little information on hazardous drinking among postpartum women. The National Health and Nutrition Survey in Japan reported that women who were hazardous drinkers comprised about $7 \%$ in their twenties $(5.9 \%$ in $2014,8.1 \%$ in $2015,7.3 \%$ in 2016 , and $5.5 \%$ in 2017 ) and about $11 \%$ in their thirties $(12.8 \%$ in $2014,9.3 \%$ in $2015,10.1 \%$ in 2016, and $11.3 \%$ in 2017) [13]. The 2013 national survey among the general population of Japan revealed that the prevalence of hazardous drinking was $4.5 \%$ among women in their twenties and $10.8 \%$ among women in their thirties [12]. Taken together, it is assumed that the prevalence of hazardous drinking 1 year after delivery observed in the present study was lower than that among women in the general population. There are at least two possible explanations for this lower prevalence. One is that reductions in women's drinking are the most pronounced during the first year postpartum, and the level of alcohol use subsequently increases with the age of the child [14]. The other is that motherhood is associated with decreased drinking overall; women with small children consume less alcohol than women without children [14, 23]. Motherhood represents a significant change in a woman's life and involves increased responsibilities and expectations. There is some evidence that transitions into traditional adult roles such as marriage and parenthood are associated with reductions in excessive drinking [24]. Being the mother of a small child may also restrict a woman's opportunities to go out for dinner or a party or to take part in other social activities in which she could drink excessively [25]. This new role and change in lifestyle may be protective against hazardous drinking. Compared with data on maternal drinking during pregnancy, limited epidemiological data are available on alcohol use during the postpartum period. The present study can contribute to the limited evidence on the prevalence of hazardous drinking during the postpartum period because it provided reliable estimates crucial for designing appropriately targeted prevention and early intervention initiatives.

Women with lower education were more likely to be hazardous drinkers. This result is inconsistent with the findings in Western countries, in which an association has been found between higher education and hazardous drinking among women in the general population [4] and among postpartum women $[6,8]$. The 2013 national survey among the general population of Japan showed that lower-educated women were more likely to be hazardous drinkers [12], which is consistent with the present finding. There are at least three possible explanations for this association. First, education conveys factual health-related knowledge and raises cognitive skills which affect health-promoting decisions [26]. The $\mathrm{Na}$ tional Health and Nutrition Survey 2015 in Japan reported that only $23.6 \%$ of women know the amount of alcohol that increases the risk of lifestyle-related disease onset for women [13]. Education may increase an understanding of the negative impacts of hazardous drinking and may build the capacity to manage drinking by stopping or keeping consumption low. Second, education shapes cultural capital in the form of health-related values and norms [27]. Because alcohol drinking is influenced by cultural norms [4], unequal distribution of cultural capital across educational levels may result in differences in alcohol drinking patterns in the social and cultural contexts in Japan [11]. Third, social networks, which combine an individual's resources with those of others [28], may partially explain the observed association. People with lower education associate with others who also have lower education, and their social networks communicate health-related behaviors [26]. Men with lower education are more likely to be hazardous drinkers in Japan [12, 29], and drinking patterns can follow social networking paths [30]. These situations would lead to the association between lower education and hazardous drinking observed in the present study.

The association between lower income and hazardous drinking disappeared after adjusting for education. This result is inconsistent with the findings in Western countries, in which an association has been found between higher income and hazardous drinking among women in the general population [4] and among postpartum women $[6,8]$. The National Health and Nutrition Survey 2014 and the 2013 national survey in the general population of Japan showed no association between income and hazardous drinking among women [12,13], which is consistent with the present finding. In Western countries, the association between higher income and hazardous drinking is often explained by the fact that affluent people have more disposable income with which to purchase alcohol [31]. However, safe and high-quality varieties of alcoholic beverage are available at relatively low prices in Japan [32], which would partially explain the lack of an association in the present study. This indicates that taxation and pricing policies may be unsuccessful in reducing hazardous drinking among postpartum women in Japan, although these policies have potential to reduce 
alcohol consumption among hazardous drinkers with lower income in Western countries [33, 34]. The present study also showed that lower income was associated with an increased risk of hazardous drinking among lower-educated women. This finding suggests that the cumulative disadvantage of lower education and lower income would increase the risk of hazardous drinking. Therefore, more attention to these populations may be needed.

The present findings have implications for the design of effective interventions aimed at preventing hazardous drinking among postpartum women. Although most women reduce or abstain from alcohol use during pregnancy [5], 3.6\% had already engaged in hazardous drinking 1 year after delivery in the present study. Hazardous drinking among postpartum women is of significant public health concern because maternal drinking can directly and indirectly damage mother and children's health even at a non-dependent level; it can negatively have impacts on child-rearing environments, increase physical and psychological harm to children, damage mother-child relationships [35], and increase the risk of alcohol-related problems later in life [36]. The second term of Health Japan 21 aims to reduce the prevalence of hazardous drinking among women from $7.5 \%$ in 2010 to $6.4 \%$ by 2022 [20]. However, this prevalence has been increasing; the prevalence was $9.1 \%$ in 2019 [13]. The first year of motherhood is the year of greatest transition and may therefore be associated with changes in drinking patterns [14], which suggests that this period provides an ideal opportunity for primary care providers to intervene. While much attention has been paid to drinking during pregnancy, much less research has focused on mothers' postpartum drinking. Although one metaanalysis demonstrated the effectiveness of psychosocial interventions to reduce alcohol consumption among mothers with dependent children, both the number of studies included and the effect found was small [37]. The present study has clarified factors that can be used to identify high-risk subpopulations of postpartum women and that can be targeted in future interventions in Japan.

Limitations of the present study should be noted. First, it was conducted in 1 of the 47 prefectures in Japan, which limits the generalizability of the findings. However, the prevalence of hazardous drinking among women in Miyagi Prefecture (8.0\% in 2016) [38] was similar to that reported from the National Health and Nutrition Survey (9.1\% in 2016) [13]. Second, approximately half of the women who agreed to participate in the TMM BirThree Cohort Study were analyzed. Women who were excluded from the analysis were less educated, had lower equivalent income, and were more likely to engage in hazardous drinking 1 year after delivery (Table S1); this may have led to underestimation of the association of education and income with hazardous drinking. Third, information on equivalent household income was obtained during pregnancy, and it is possible that the women's income changed between the pregnancy periods and 1 year after delivery. Fourth, as in most epidemiological studies, the participants' drinking status was self-reported. Women may be influenced by social desirability, a bias that is important especially when questions address socially undesirable attitudes and behaviors. However, one review concluded that a self-report method is a reliable and valid approach to measuring alcohol consumption [39]. Additionally, one study showed that correction of self-reporting bias did not change the direction of educational differences in hazardous drinking among Japanese women [40]. Finally, because of data limitations, we could not examine the associations of education and income with heavy episodic drinking (defined as ethanol intake of $\geq 60 \mathrm{~g}$ on at least one occasion at least once per month) [2]. These associations would differ from those observed in the present study because heavy episodic drinking is different from other forms of drinking such as hazardous drinking, in that the intention is to drink a harmful amount of alcohol [4].

\section{Conclusion}

The present study showed that the prevalence of hazardous drinking 1 year after delivery was 3.6\%. Lower education was associated with an increased risk of hazardous drinking. Although the association between lower income and hazardous drinking disappeared after adjusting for education, this association remained only in a lower education group. Our findings can provide clues to designing effective interventions for preventing hazardous drinking among postpartum women, which would improve maternal and child health.

\section{Abbreviations \\ 95\% Cl: 95\% confidence interval; OR: Odds ratio; TMM BirThree Cohort Study: Tohoku Medical Megabank Project Birth and Three-Generation Cohort Study}

\section{Supplementary Information}

The online version contains supplementary material available at https://doi. org/10.1186/s12199-021-00991-9.

Additional file 1: Table S1. Characteristics differences between 11,031 participants who were analyzed and 11,462 participants who were excluded from the analysis Table S2. Associations of education and income with hazardous drinking 1 year after delivery among drinkers

\section{Acknowledgements}

The authors wish to express their appreciation to the pregnant women who participated in the TMM BirThree Cohort Study. 


\section{Authors' contributions}

KM was responsible for the study conception, design, analysis, and interpretation of the data, as well as the drafting of the manuscript. SK provided advice regarding critically important intellectual content and helped to draft the manuscript. All authors acquired the data and intensively revised the manuscript. The authors read and approved the final manuscript.

\section{Funding}

The Tohoku Medical Megabank Project Birth and Three-Generation Cohort Study was supported by the Japan Agency for Medical Research and Development (AMED), Japan [grant number, JP20km0105001]. This study was supported by a Grant-in-Aid for Early-Career Scientists [grant number, 18K17397] from the Ministry of Education, Culture, Sports, Science and Technology, Japan.

\section{Availability of data and materials}

The data obtained through the TMM BirThree Cohort Study are incorporated into the TMM biobank. All data analyzed during the present study are available for research purpose with the approval by the Sample and Data Access Committee of the Biobank.

\section{Declarations}

\section{Ethics approval and consent to participate}

The TMM BirThree Cohort Study protocol was reviewed and approved by the Ethics Committee of Tohoku University Tohoku Medical Megabank Organization (2013-1-103-1). Trained genome medical research coordinators were placed in each clinic, hospital, or community support center to provide information on the TMM BirThree Cohort Study to potential participants and to receive signed informed consent forms from those who agreed to participate.

\section{Consent for publication}

There are no details on individual participants within the manuscript.

\section{Competing interests}

The authors declare that they have no competing interests.

\section{Author details}

${ }^{1}$ Tohoku Medical Megabank Organization, Tohoku University, 2-1 Seiryo-machi, Aoba-ku, Sendai, Miyagi 980-8573, Japan. ${ }^{2}$ Graduate School of Medicine, Tohoku University, 2-1 Seiryo-machi, Aoba-ku, Sendai, Miyagi 980-8575, Japan. ${ }^{3}$ Department of Pharmaceutical Sciences, Tohoku University Hospital, 1-1 Seiryo-machi, Aoba-ku, Sendai, Miyagi 980-8574, Japan. ${ }^{4}$ Division of Public Health, Hygiene and Epidemiology, Faculty of Medicine, Tohoku Medical and Pharmaceutical University, 1-15-1 Fukumuro, Miyagino-ku, Sendai, Miyagi 983-8536, Japan. ${ }^{5}$ Department of Disaster Public Health, International Research Institute of Disaster Science, Tohoku University, 2-1 Seiryo-machi, Aoba-ku, Sendai, Miyagi 980-8573, Japan.

\section{Received: 29 March 2021 Accepted: 20 June 2021}

Published online: 03 July 2021

\section{References}

1. GBD 2016 Alcohol Collaborators. Alcohol use and burden for 195 countries and territories, 1990-2016: a systematic analysis for the Global Burden of Disease Study 2016. Lancet. 2018;392:1015-35.

2. World Health Organization. Global status report on alcohol and health 2018. Geneva: World Health Organization; 2018.

3. Rehm J, Gmel GE Sr, Gmel G, Hasan O, Imtiaz S, Popova S, et al. The relationship between different dimensions of alcohol use and the burden of disease-an update. Addiction. 2017;112(6):968-1001. https://doi.org/1 0.1111/add.13757.

4. Organisation for Economic Co-operation and Development. Tackling harmful alcohol use: economics and public health policy. Paris: OECD Publishing; 2015

5. Schölin L. Prevention of harm caused by alcohol exposure in pregnancy: rapid review and case studies from member states. Copenhagen: WHO Regional Office for Europe; 2016.
6. Liu W, Mumford EA, Petras H. Maternal alcohol consumption during the perinatal and early parenting period: a longitudinal analysis. Matern Child Health J. 2016;20(2):376-85. https://doi.org/10.1007/s10995-015-1836-5.

7. Maloney E, Hutchinson D, Burns L, Mattick RP, Black E. Prevalence and predictors of alcohol use in pregnancy and breastfeeding among Australian women. Birth. 2011;38(1):3-9. https://doi.org/10.1111/j.1523-53 6X.2010.00445.X

8. Laborde ND, Mair C. Alcohol use patterns among postpartum women. Matern Child Health J. 2012;16(9):1810-9. https://doi.org/10.1007/s10995011-0925-3.

9. De Genna NM, Goldschmidt L, Marshal M, Day NL, Cornelius MD. Maternal age and trajectories of risky alcohol use: a prospective study. Alcohol Clin Exp Res. 2017:41(10):1725-30. https://doi.org/10.1111/acer.13451.

10. Tran NT, Najman JM, Hayatbakhsh R. Predictors of maternal drinking trajectories before and after pregnancy: evidence from a longitudinal study. Aust N Z J Obstet Gynaecol. 2015;55(2):123-30. https://doi.org/10.1111/a jo.12294.

11. Sudhinaraset M, Wigglesworth C, Takeuchi DT. Social and cultural contexts of alcohol use: influences in a social-ecological framework. Alcohol Res. 2016;38(1):35-45.

12. Kinjo A, Kuwabara Y, Minobe R, Maezato H, Kimura M, Higuchi S, et al. Different socioeconomic backgrounds between hazardous drinking and heavy episodic drinking: prevalence by sociodemographic factors in a Japanese general sample. Drug Alcohol Depend. 2018;193:55-62. https:// doi.org/10.1016/j.drugalcdep.2018.08.015.

13. Ministry of Health, Labour and Welfare. National Health and Nutrition Survey in Japan. https://www.mhlw.go.jp/bunya/kenkou/kenkou_eiyou_chousa. html (in Japanese) Accessed 7 Jun 2021.

14. Borschmann R, Becker D, Spry E, Youssef GJ, Olsson CA, Hutchinson DM, et al. Cannabis Cohorts Research Consortium. Alcohol and parenthood: an integrative analysis of the effects of transition to parenthood in three Australasian cohorts. Drug Alcohol Depend. 2019;197:326-34. https://doi. org/10.1016/j.drugalcdep.2019.02.004.

15. Kuriyama S, Metoki H, Kikuya M, Obara T, Ishikuro M, Yamanaka C, et al. Cohort profile: Tohoku Medical Megabank Project Birth and ThreeGeneration Cohort Study (TMM BirThree Cohort Study): rationale, progress and perspective. Int J Epidemiol. 2020;49:18-9.

16. Murakami K, Ueno F, Nakamura I, Ishikuro M, Noda A, Onuma T, et al. Maternal personality and postnatal bonding disorder in Japan: the Tohoku Medical Megabank Project Birth and Three-Generation Cohort Study. J Affect Disord. 2020;282:580-6.

17. Kuriyama S, Yaegashi N, Nagami F, Arai T, Kawaguchi Y, Osumi N, et al. The Tohoku Medical Megabank Project: design and mission. J Epidemiol. 2016; 26(9):493-511. https://doi.org/10.2188/jea.JE20150268.

18. Atkinson AB, Rainwater $L$, Smeeding TM. Income distribution in OECD countries: evidence from the Luxembourg Income Study. Paris: Organization for Economic Co-operation and Development; 1995.

19. Yokoyama Y, Takachi R, Ishihara J, Ishii Y, Sasazuki S, Sawada N, et al. Validity of short and long self-administered food frequency questionnaires in ranking dietary intake in middle-aged and elderly Japanese in the Japan Public Health Center-Based Prospective Study for the Next Generation (JPHC-NEXT) protocol area. J Epidemiol. 2016;26(8):420-32. https://doi.org/1 0.2188/jea.JE20150064.

20. Ministry of Health, Labour and Welfare. 2012. Reference material for the promotion of Health Japan 21 (the second term). http://www.mhlw.go. jp/bunya/kenkou/dl/kenkounippon21_02.pdf (in Japanese) Accessed 7 Jun 2021.

21. Cox JL, Holden JM, Sagovsky R. Detection of postnatal depression. Development of the 10-item Edinburgh Postnatal Depression Scale. Br J Psychiatry. 1987;150(6):782-6. https://doi.org/10.1192/bjp.150.6.782.

22. Okano T, Murata M, Msuji F, Tamaki R, Nomura J, Miyaoka H, et al. Validation and reliability of Japanese version of the EPDS. Arch Psychiatr Diagn Clin Eval. 1996;7:525-33 [article in Japanese with English abstract].

23. McKetta S, Keyes KM. Heavy and binge alcohol drinking and parenting status in the United States from 2006 to 2018: an analysis of nationally representative cross-sectional surveys. PLoS Med. 2019;16(11):e1002954. https://doi.org/10.1371/journal.pmed.1002954.

24. Leonard KE, Eiden RD. Marital and family processes in the context of alcohol use and alcohol disorders. Annu Rev Clin Psychol. 2007;3(1):285-310. https:// doi.org/10.1146/annurev.clinpsy.3.022806.091424. 
25. Paradis C. Parenthood, drinking locations and heavy drinking. Soc Sci Med. 2011;72(8):1258-65. https://doi.org/10.1016/j.socscimed.2011.02.025.

26. Glymour MM, Avendano M, Kawachi I. Socioeconomic status and health. In: Berkman LF, Kawachi I, Glymour MM, editors. Social epidemiology. New York: Oxford University Press; 2014. p. 17-62.

27. Abel T. Cultural capital and social inequality in health. J Epidemiol Community Health. 2008;62(7):e13. https://doi.org/10.1136/jech.2007.066159.

28. Berkman LF, Krishna A. Social network epidemiology. In: Berkman LF, Kawachi I, Glymour MM, editors. Social epidemiology. New York: Oxford University Press; 2014. p. 234-89.

29. Murakami K. Hashimoto H Associations of education and income with heavy drinking and problem drinking among men: evidence from a population-based study in Japan. BMC Public Health. 2019;19(1):420. https:// doi.org/10.1186/s12889-019-6790-5.

30. Rosenquist JN, Murabito J, Fowler JH, Christakis NA. The spread of alcohol consumption behavior in a large social network. Ann Intern Med. 2010; 152(7):426-33. https://doi.org/10.7326/0003-4819-152-7-201004060-00007.

31. Wagenaar AC, Salois MJ, Komro KA. Effects of beverage alcohol price and tax levels on drinking: a meta-analysis of 1003 estimates from 112 studies. Addiction. 2009;104(2):179-90. https://doi.org/10.1111/j.1360-0443.2008.0243 8.x.

32. Higuchi S, Matsushita S, Maesato H, Osaki Y. Japan: alcohol today. Addiction. 2007;102(12):1849-62. https://doi.org/10.1111/j.1360-0443.2007.01902.x.

33. Herttua K, Mäkelä P, Martikainen P. Changes in alcohol-related mortality and its socioeconomic differences after a large reduction in alcohol prices: a natural experiment based on register data. Am J Epidemiol. 2008;168(10): 1110-8. https://doi.org/10.1093/aje/kwn216.

34. Holmes J, Meng Y, Meier PS, Brennan A, Angus C, Campbell-Burton A, et al. Effects of minimum unit pricing for alcohol on different income and socioeconomic groups: a modelling study. Lancet. 2014;383(9929):1655-64. https://doi.org/10.1016/50140-6736(13)62417-4

35. McGovern R, Gilvarry E, Addison M, Alderson H, Carr L, Geijer-Simpson E, et al. Addressing the impact of nondependent parental substance misuse upon children: a rapid review of the evidence of prevalence, impact and effective interventions. London: Public Health England; 2018.

36. Yap M, Cheong T, Zaravinos-Tsakos F, Lubman DI, Jorm AF. Modifiable parenting factors associated with adolescent alcohol misuse: a systematic review and meta-analysis of longitudinal studies. Addiction. 2017;112(7): 1142-62. https://doi.org/10.1111/add.13785.

37. Ujhelyi GK, Goodwin L, Jackson L, Jones A, Chisholm A, Rose AK. Are psychosocial interventions effective in reducing alcohol consumption during pregnancy and motherhood? A systematic review and meta-analysis. Addiction. 2021;116:1638-63.

38. Miyagi Prefectural Government. Health and Nutrition Survey in Miyagi Prefecture. https://www.pref.miyagi.jp/soshiki/kensui/kenmin-tyousa.html (in Japanese) Accessed 7 Jun 2021.

39. Del Boca FK, Darkes J. The validity of self-reports of alcohol consumption: state of the science and challenges for research. Addiction. 2003;98(Suppl 2):1-12. https://doi.org/10.1046/j.1359-6357.2003.00586.x.

40. Devaux M, Sassi F. Social disparities in hazardous alcohol use: self-report bias may lead to incorrect estimates. Eur J Public Health. 2016;26(1):129-34. https://doi.org/10.1093/eurpub/ckv190.

\section{Publisher's Note}

Springer Nature remains neutral with regard to jurisdictional claims in published maps and institutional affiliations.

Ready to submit your research? Choose BMC and benefit from:

- fast, convenient online submission

- thorough peer review by experienced researchers in your field

- rapid publication on acceptance

- support for research data, including large and complex data types

- gold Open Access which fosters wider collaboration and increased citations

- maximum visibility for your research: over $100 \mathrm{M}$ website views per year

At BMC, research is always in progress.

Learn more biomedcentral.com/submissions 